\title{
Meet Our New Field Editor
}

\section{Kostas Fountoulakis}

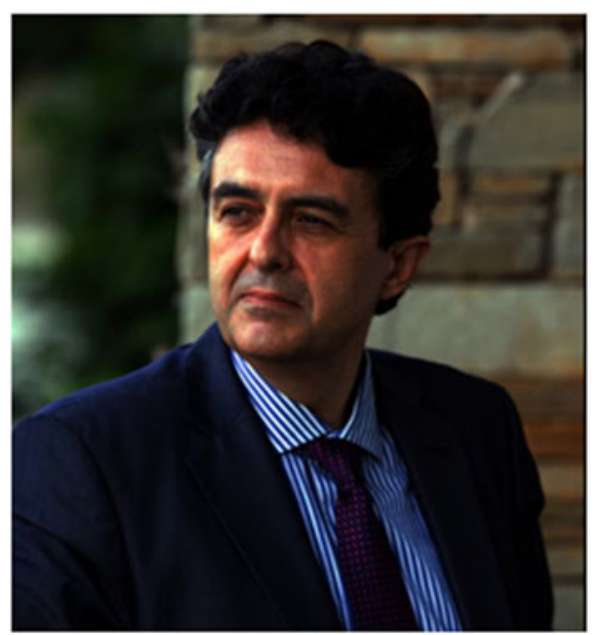

Dr. Kostas Fountoulakis received his medical degree in 1989, performed his residency in psychiatry in 1998, and earned his doctorate in psychiatry in 1999 at the Aristotle University of Thessaloniki. He was also a Research Fellow in the Department of Psychiatry, Division of Neuropsychiatry, at the University of Geneva in Switzerland in 2005. Dr. Fountoulakis' areas of clinical and research interest are reflected in the topics that he teaches, which include general psychiatry, biological psychiatry, psychopharmacology, mood disorders, schizophrenia and personality disorders. He has coauthored more than 400 papers and more than 250 of them are published in several international journals such as the LANCET, BMJ, American Journal of Psychiatry, British Journal of Psychiatry, Biological Psychiatry,
International Journal of Neuropsychopharmacology, Journal of Affective Disorders, Schizophrenia Research, Psychiatry Research, Bipolar Disorders, and the Annals of General Psychiatry among others, with approximately 10,000 citations and $\mathrm{h}=50$ (Publish or Perish). During the years 2016-2018, he was ranked by expertscape.com as being within the top 25 world experts concerning bipolar disorder $(0.068 \%)$ and among the top 50 concerning suicidality $(0.097 \%)$. He has received a number of national and international research awards, including the 2012 Kraepelin-Alzheimer medal of the University of Munich and the 2015 Excellence in Education Award of the WFSBP. Since 2014, he has been an honorary member of the World Psychiatric Association. 